\title{
Ethics In Knowledge Management As A Research Agenda
}

\author{
Sanil S Hishan, Ezzat Abdulaziz Mansour, Suresh Ramakrishnan, Nur Naha Binti Abu Mansor
}

\begin{abstract}
Knowledge Management is the process of capturing, distributing and distributing knowledge effectively. In the last few decades with the rise in information technology and advances in Knowledge Management, ethics in knowledge management is one of the important areas to be researched. The present study uses the Scopus database to analyze the research trends in this area. The findings highlighted that there are less than $10 \%$ studies in the area of knowledge management and ethics. The study finding has shown that although there is a rise in the studies in this area, the ethics in knowledge management is one area which needs to be explored.
\end{abstract}

Index Terms: Knowledge Management, Scopus database, Ethics, Social Responsibility.

\section{INTRODUCTION}

The concept of Knowledge Management (KM) came to existence since the rise of internet. One of the simple definitions about KM is given by Davenport, (1994) [1], as per this definition "Knowledge Management is the process of capturing, distributing, and effectively using knowledge." One of seminal paper on KM was authored by Einhorn (1915) [2]. Ethics is KM is an area where the ethics related to knowledge sharing, protecting intellectual capital of individuals and corporate intelligence of organisations, as well as social and cultural sensitivity is studied. This paper explores the research trends over the past two decades to understand the research progress in this area.

\section{LITERATURE REVIEW}

Ethics relates to codes of conduct regarded as right and good, based on morality or values, faith or some higher authority. Ethical principles are rarely absolute but are "relativistic and arise out of particular situations" [3] . As with many discussions of ethics or moral reasoning, clear determinations are complicated by conflicting rights. Determining right from wrong in a knowledge management process pertains to knowledge sharing, protecting intellectual capital of individuals and corporate intelligence of organisations, as well as social and cultural sensitivity. A teleological approach considers the ultimate consequences of human actions in order to resolve ethical dilemmas, while deontology denotes that some kinds of action are in themselves wrong, despite the consequences of the actions.

Revised Manuscript Received on April 19, 2019.

Sanil S Hishan, Azman Hashim International Business School (AHIBS), Universiti Teknologi Malaysia, Malaysia.

Ezzat Abdulaziz Mansour, Department of information science, King Abdulaziz University,Saudi Arabia.

Suresh Ramakrishnan, Azman Hashim International Business School (AHIBS), Universiti Teknologi Malaysia, Malaysia.

Nur Naha Binti Abu Mansor, Azman Hashim International Business School (AHIBS), Universiti Teknologi Malaysia, Malaysia.
In other words, deontology refers to "doing the right thing" while teleology is concerned with achieving the desired outcome from the actions [4]. In the teleological approach actions are right if they have good consequences ('the end justifies the means') and wrong if they have bad consequences [5].

\section{METHOD}

The study used a systematic literature review approach to study the research trends in the field of ethics and knowledge management. The researcher used two key words Knowledge Management, Knowledge Management and Ethics to search for the articles related to this area. The study included only the articles indexed in SCOPUS database and published between the year 2000 to 2018, to understand the research trend in the new millennium[6]-[7]. A total of 2,71,164 article related to KM was included for this study. The articles were then analyzed using the Scopus database feature of analysis search. The articles which were on ethics in KM was further analyzed by reading the content and analyzing the area of research and their conclusions.

\section{FINDINGS}

Based on the analysis of the articles published in the Scopus database. The figure 1 shows the number of articles published in the area of KM between the year $2000-2018$. However, as per scopus database, the first article was published in the year 1915 in the area of KM.

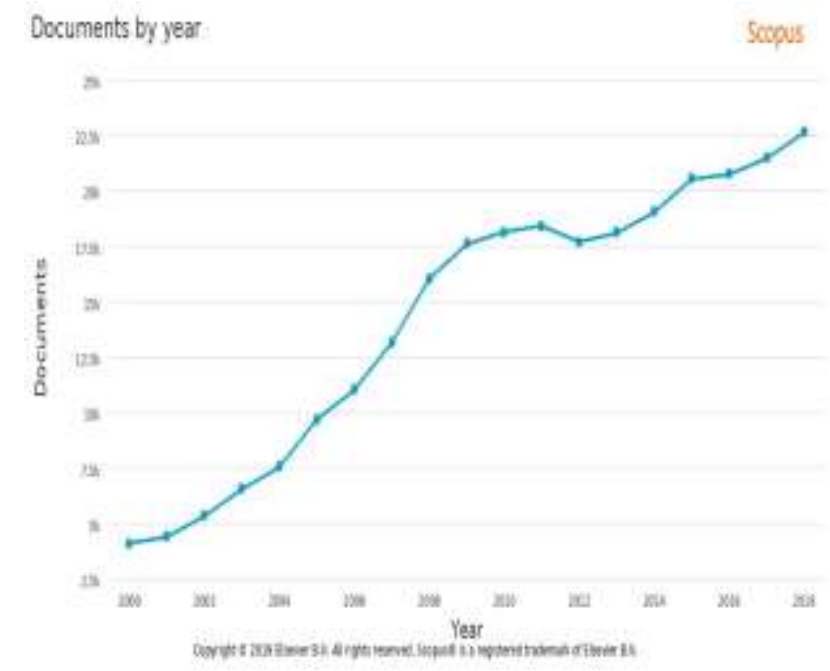

Figure 1: Year Wise Published Article In Km (2000 2018)

Published By:

Blue Eyes Intelligence Engineering

\& Sciences Publication 
International Conference on Recents Advancements in Engineering and Technology (ICRAET-18) |15th and 16th March 2019|Siddhartha Institute of Technology \& Sciences, Telangana, India.

The table 1 shows the year wise breakdown of the article published in the area of KM. As per the scopus data base analysis, it has around 27164 articles published in the scopus database between the year $2000-2018$. The number of articles has seen an upward trend and continuing to increase year by year. Similarly, the figure 2 shows the country wise breakup of the articles published and indexed in scopus. The data shows that highest number of articles published in the area of KM is from the United States, followed by United Kingdom and China. The figure 3 shows some of the prominent authors in the field of KM. Similarly figure 4 shows the breakdown of the article published based on the subject area and it is clear that in the area of business management there are only $9.5 \%$ of the total articles published and indexed in scopus in the area of KM. Majority of the articles published in the area of KM is in the area of Medicine (16.5\%) and computer science (15.7\%).
Table 1: Breakdown of the KM articles published and indexed in scopus database (2000-2018)

\begin{tabular}{|c|c|}
\hline YEAR & No of Article \\
\hline 2018 & 22622 \\
\hline 2017 & 21441 \\
\hline 2016 & 20727 \\
\hline 2015 & 20512 \\
\hline 2014 & 19023 \\
\hline 2013 & 18086 \\
\hline 2012 & 17664 \\
\hline 2011 & 18376 \\
\hline 2010 & 18101 \\
\hline 2009 & 17572 \\
\hline 2008 & 16008 \\
\hline 2007 & 13117 \\
\hline 2006 & 11011 \\
\hline 2005 & 9643 \\
\hline 2004 & 7526 \\
\hline 2003 & 6520 \\
\hline 2002 & 5292 \\
\hline 2001 & 4372 \\
\hline 2000 & 4061 \\
\hline Total & 271674 \\
\hline
\end{tabular}

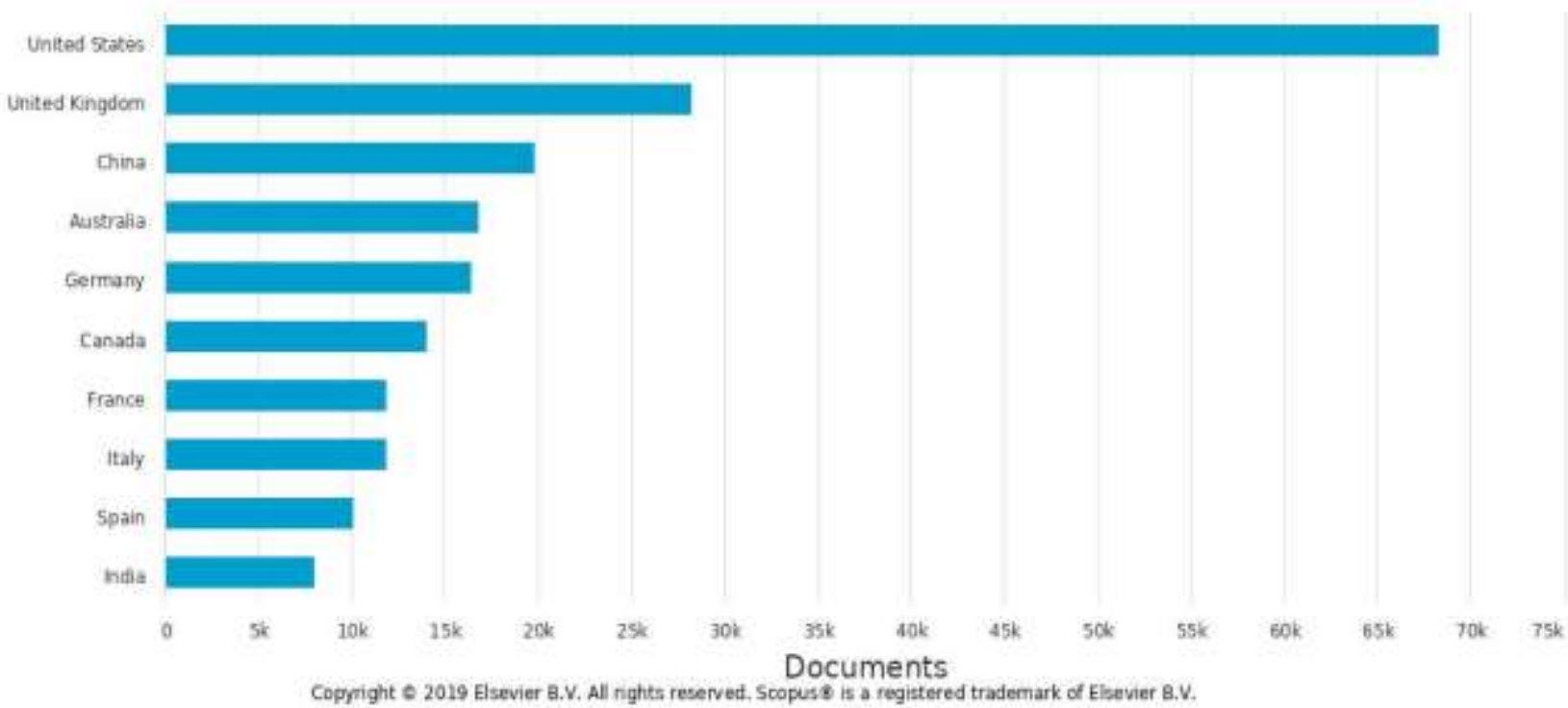

Figure 2: Country wise published article in KM (2000 -2018) 


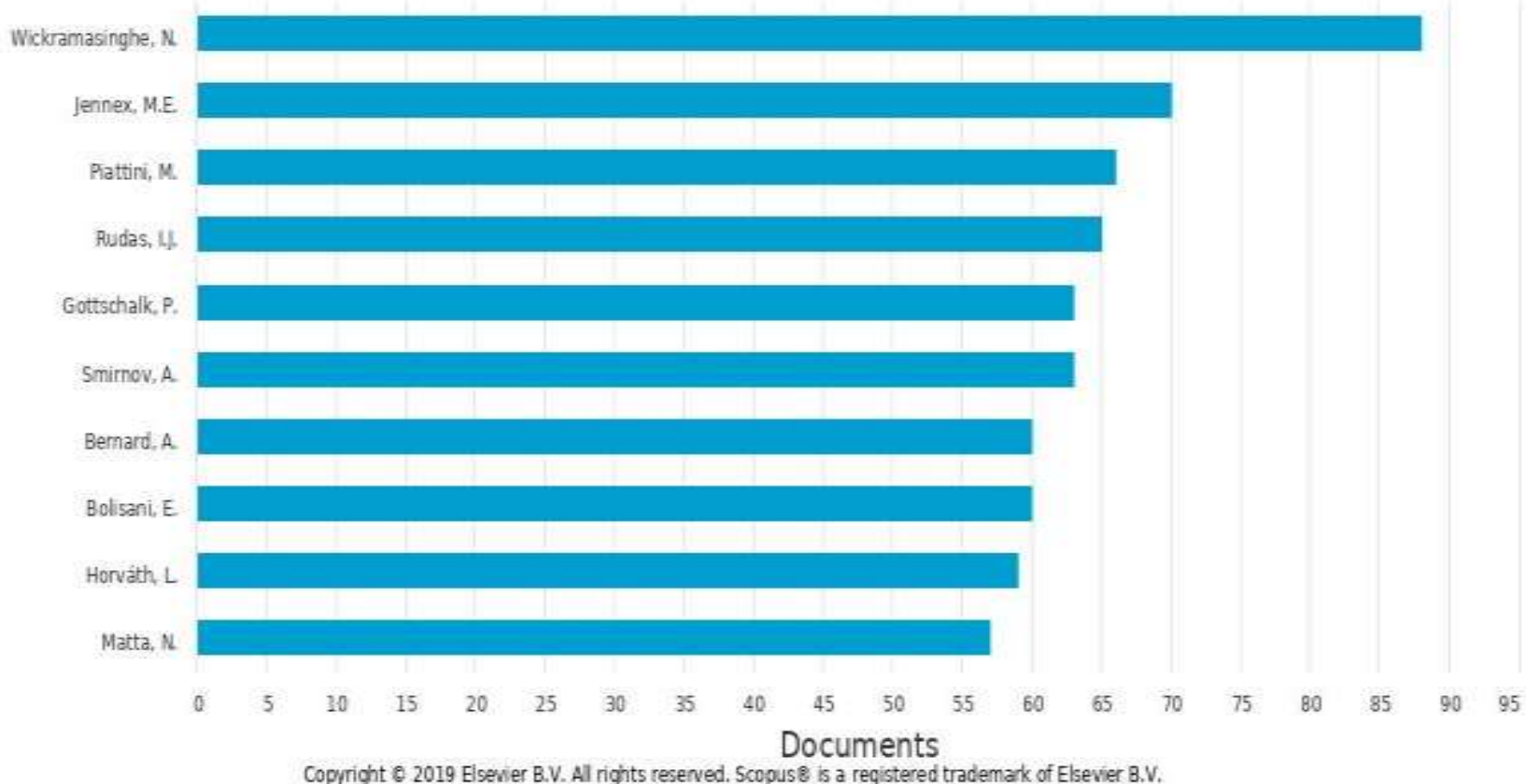

Figure 3: Author wise published article in KM (2000 -2018)

Documents by subject area

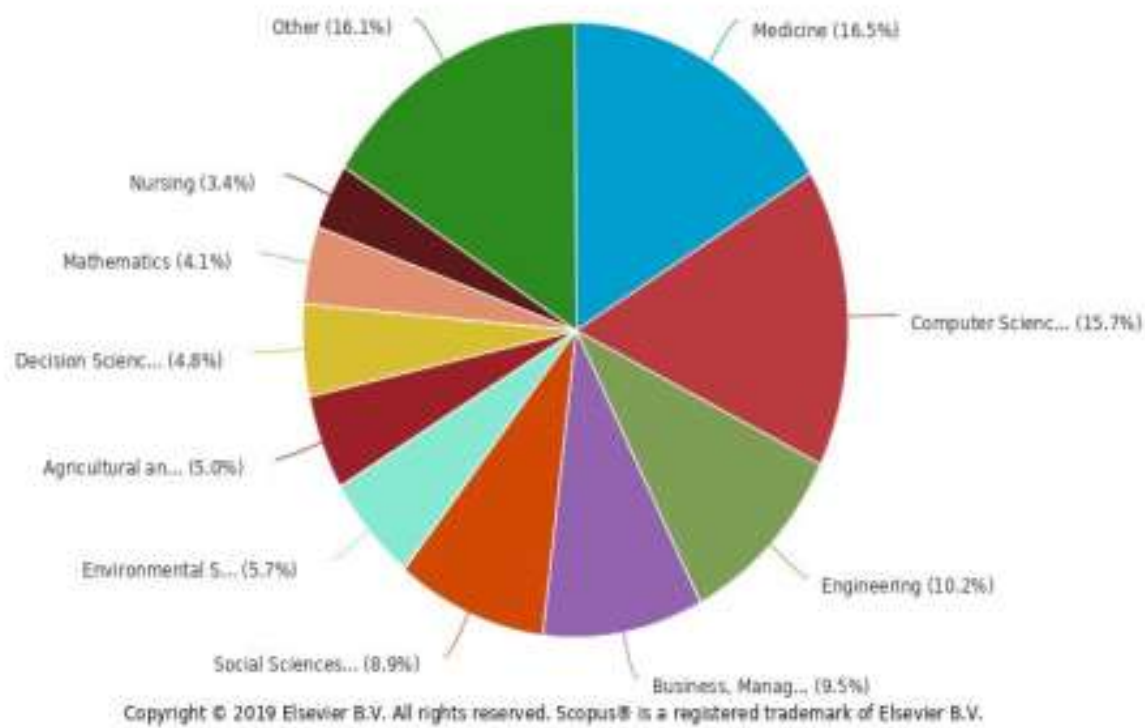

Figure 4: Subject area wise published article in KM (2000 -2018)

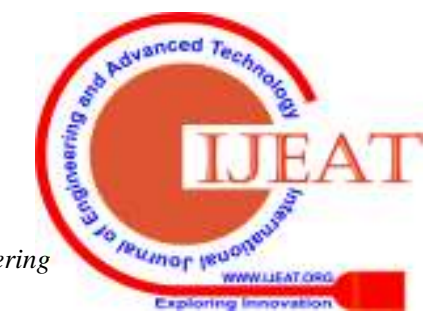


International Conference on Recents Advancements in Engineering and Technology (ICRAET-18) |15th and 16th March 2019|Siddhartha Institute of Technology \& Sciences, Telangana, India.

Table 2: Breakdown of the Ethics in KM articles published and indexed in scopus database (2000-2018)

\begin{tabular}{|l|l|}
\hline YEAR & No of articles \\
\hline 2018 & 256 \\
\hline 2017 & 267 \\
\hline 2016 & 221 \\
\hline 2015 & 251 \\
\hline 2014 & 196 \\
\hline 2013 & 194 \\
\hline 2012 & 185 \\
\hline 2011 & 162 \\
\hline 2010 & 183 \\
\hline 2009 & 192 \\
\hline 2008 & 183 \\
\hline 2007 & 171 \\
\hline 2006 & 158 \\
\hline 2005 & 118 \\
\hline 2004 & 82 \\
\hline 2003 & 94 \\
\hline 2002 & 86 \\
\hline 2001 & 54 \\
\hline 2000 & 54 \\
\hline Total & 3107 \\
\hline
\end{tabular}

Documents by year

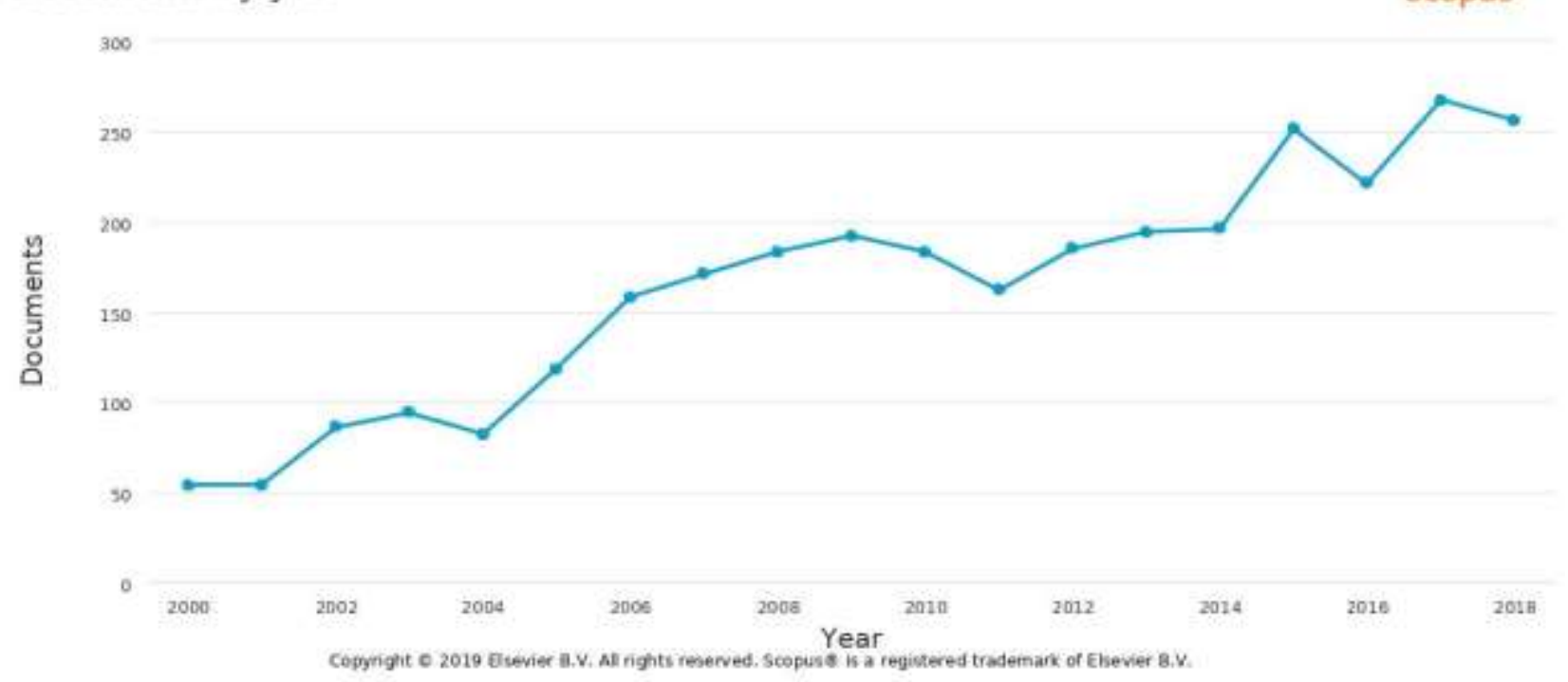

Figure 5: Year wise published article in Ethics in KM (2000 -2018)

The figure 5 shows the number of articles published and indexed in the scopus database in the area of ethics in KM. As in the case of KM, even in the area of ethics in KM the number of articles published has seen an increasing trend. The table 2, shows the year wise breakdown of the articles published in the scopus database in the area of ethic in KM. As per the table 2 a total of only 3107 articles are published in the area of ethics in KM. Although there is a upward trend in researches in this area, it is very less as compared to the research papers published in the area of KM. As
The above four analysis clearly suggests that not many researches is conducted in the area of $\mathrm{KM}$ in the Asian context as majority of the published articles are from the western countries. Moreover, the findings also highlight that not many articles are published in the area of business and management. However, the research in the area of KM has shown an upward trend in the last two decades. The analysis shows that from only 4061 articles in the year 2000, presently around 22622 articles are published and indexed in Scopus. Similarly, the analysis was conducted on the articles published in the area of ethics in KM. compared to the number of articles published in 2017, there is a reduction in the articles published in 2018.

The figure 6 shows the country wise breakup of the articles published in are of ethics in KM. The findings clearly shows that the research on ethics in KM is conducted majorly in the developed countries and US leads the list. 


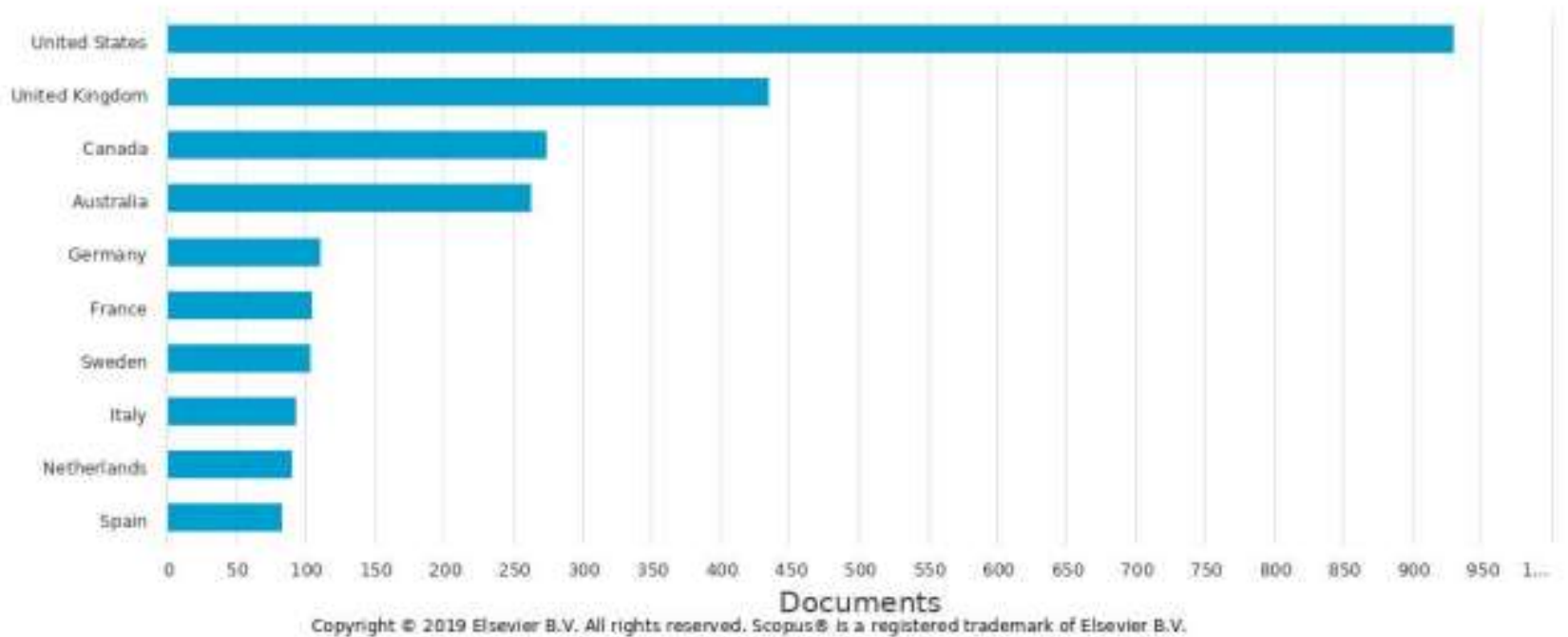

Figure 6: Country wise published article in Ethics in KM (2000 -2018)

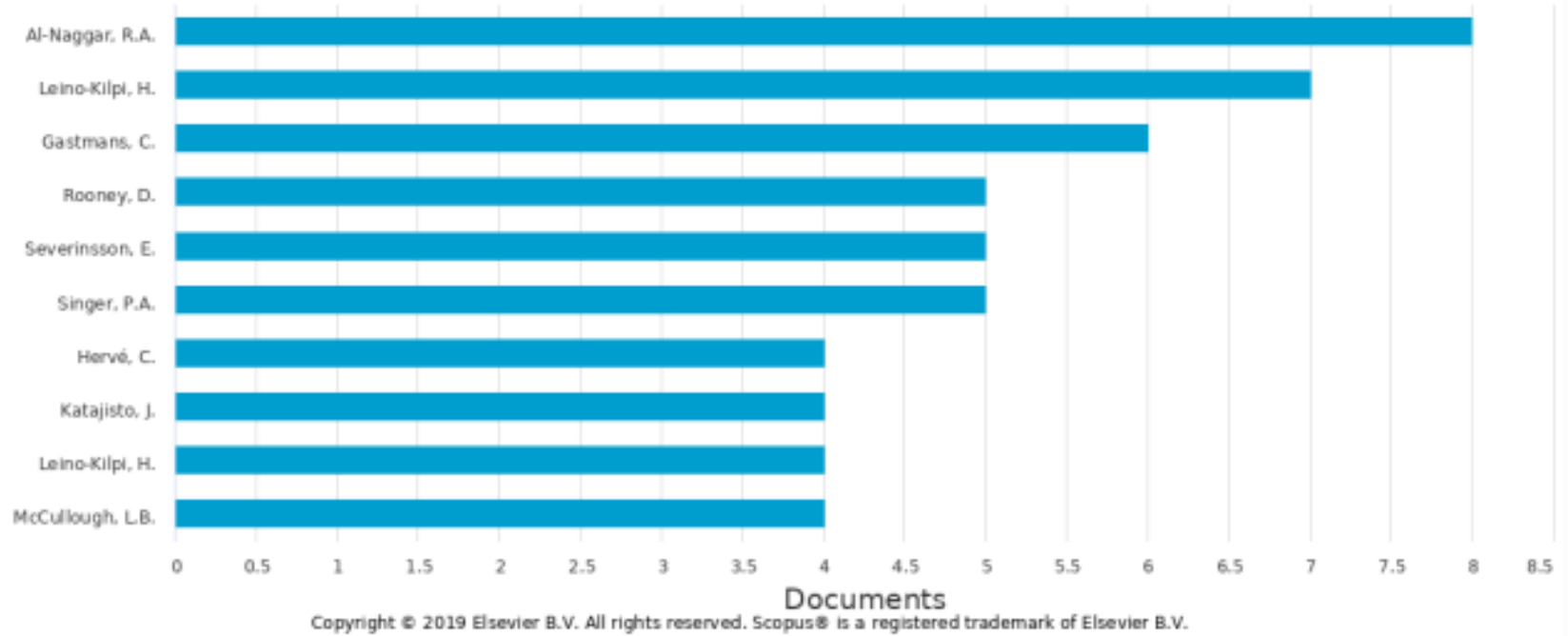

Figure 7: Author wise published article in Ethics in KM (2000 -2018)

The author wise breakup shows that maximum number of articles on ethics in KM is from the author Al-Naggaar R A. However, even in this case it is very clear that the research on ethics and $\mathrm{KM}$ is scarce and especially there is a lack of such studies in the Asian context.

\section{CONCLUSION}

Ethics in Knowledge Management is one of the unexplored areas of research. The findings from the scopus search analysis has shown that there is lack of studies in this area and majority of the study is conducted by the researchers in the US. However, this becomes an important topic to study in the Asian context as the use of internet has made the Asian countries an important partner for trade. It must be also noted that Asian countries play an important role in Information Technology and Knowledge sharing is a very important part of any business these days. Hence, the awareness of ethics in knowledge management can play a vital role in all the areas of ethics in KM, i.e. knowledge sharing, protecting intellectual capital of individuals and corporate intelligence of organisations, as well as social and cultural sensitivity. Therefore, it can be concluded that ethics in $\mathrm{KM}$ is an important research agenda especially in the Asian context, countries like India, China, Malaysia and other Asian countries have to conducted some research studies in this area as ethics in knowledge management is very important in this globalised business world. One of the limitations of this study is that it considered only the articles indexed in scopus database, however future studies can be conducted using other databases like Web of Science and google scholars. Another limitation of this study is the method of analysis was only based on simple descriptive statistics and future studies can go further and use content analysis as a measure.

Published By:

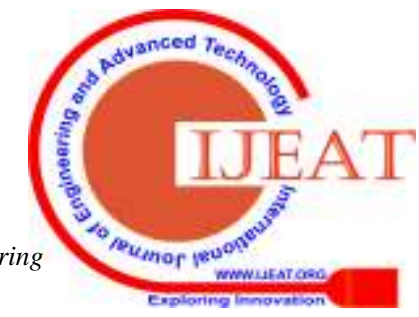


International Conference on Recents Advancements in Engineering and Technology (ICRAET-18) |15th and 16th March 2019|Siddhartha Institute of Technology \& Sciences, Telangana, India.

\section{REFERENCES}

1. Davenport TH. Managing in the new world of process. Public Productivity \& Management Review. 1994 Dec $1: 133-47$.

2. Einhorn M. A Clinical Contribution to our Knowledge of Chronic Pancreatitis. Journal of the American Medical Association. $1915 \mathrm{Jul}$ 10;65(2):149-53.

3. Harshman CL, Harshman EF. The Gordian knot of ethics: Understanding leadership effectiveness and ethical behavior. Journal of business Ethics. 2008 Mar 1;78(1-2):175-92.

4. Gordon-Till J. Ethics: the professional challenge Business Information Review. 2002 Dec;19(4):46-54.

5. Mulvany N, Farrow J. The Indexer. Indexer. 1995 Oct $18 ; 19(4): 241$.

6. Qureshi MI, Yusoff RM, Hishan SS, Alam AF, Zaman K, Rasli AM. Natural disasters and Malaysian economic growth: policy reforms for disasters management. Environmental Science and Pollution Research. 2019 May 1;26(15):15496-509.

7. Alsolami B, Embi MR. Crowding perception: A case study of developed systematic literature review procedure with multiple software programs as management and synthesis tools. International Journal of Engineering \& Technology. 2018;7(2.10):121-6.

\section{AUTHORS PROFILE}
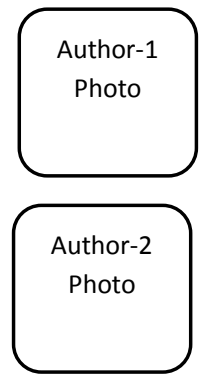

Author-3

Photo

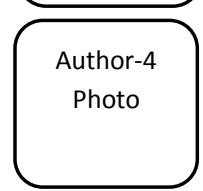

Sanil S Hishan, Azman Hashim International Business School (AHIBS), Universiti Teknologi Malaysia, Malaysia.

Ezzat Abdulaziz Mansour, Department of information science, King Abdulaziz University,Saudi Arabia.

Suresh Ramakrishnan, Azman Hashim International Business School (AHIBS), Universiti Teknologi Malaysia, Malaysia.

Nur Naha binti Abu Mansor, Azman Hashim International Business School (AHIBS), Universiti Teknologi Malaysia, Malaysia. 